\title{
ACER's Success in Establishing and Ensuring the Functioning of the Internal Energy Market: Through the Eyes of NRAS and Traders
}

\author{
Alenka Lena Klopčič \\ Montel Energetika.net, Slovenia \\ alenka-lena.klopcic@energetika.net \\ Jana Hojnik \\ Faculty of Management, University of Primorska, Slovenia \\ jana.hojnik@fm-kp.si \\ Aleš Pustovrh \\ Faculty of Economics, University of Ljubljana, Slovenia \\ ales.pustovrh@ef.uni-lj.si
}

The Agency for the Cooperation of Energy Regulators (ACER) was launched in 2011 to contribute to the establishment and functioning of the EU's internal energy market. This study aims to evaluate ACER's success in establishing and ensuring the functioning of the internal energy market, both from ACER's and its stakeholders' (energy regulators and energy traders in the $\mathrm{EU}$ member states) perspective. The paper includes the results of interviews with nine national regulatory authorities (NRAS) and ten energy traders from the EU member states. This research revealed that, based on their perception, ACER is actually crucial for the operation of the internal market. In addition, NRAs and energy traders mostly agree that the $\mathrm{EU}$ has a nearly functional internal energy market and that ACER is vitally important for the functioning of the internal market.

Key Words: regulator, internal energy market, EU, functioning, ACER JEL Classification: K32, L43, F16, G14

https://doi.org/10.26493/1854-6935.18.91-110

\section{Introduction}

Over the past few decades, as developing economies have struggled to pull their populations out of poverty, electricity sector restructuring has been regarded as a crucial facilitating factor for higher levels of economic development (Ebrahimian et al. 2018). However, although the international environment imposes constraints on countries, especially on the economically backward ones, it does not solely determine the dependency and developmental performance of a country (Rončević et al. 
2010). According to Felder (2016), electricity markets are intertwined with engineering - perhaps even more so than other markets - meaning that power system engineering cannot be completely separated from microeconomics, neither in theory nor in practice. The restructuring of the electric power industry in the 199 os began with the key objective of establishing market-based decision-making in energy investment, despite the accompanying market risks. The aim was to have market forces, rather than bureaucrats, act as the drivers, and to have investors, rather than ratepayers, bear the risks, explained Léautier (2016). The reason for that is simple - such markets are presumed to be more efficient than the alternatives. In the world of perfect competition, the market's innate coordination mechanisms would allocate goods and services efficiently. They would reach the Pareto optimum (Arrow and Debreu 1954).

Electricity has characteristics of a public good as it spills over from producer to other players (consumers), who are only limited by their capabilities in utilising it. This results in an appropriability problem for producers of electricity. Electricity-producing companies cannot fully appropriate the returns on their investment and will hence under-invest in the production of electricity. This reasoning is based on the classical view that goes back to Smith (1845) and neoclassical economics. According to these views, the target for governments is to establish conditions for competition that will channel individual self-interest for the common good.

However, after long, wide trends toward freer and more integrated markets, peoples and ideas, reluctance to subordinate the ideals of globalization to state interests (Quirk 2008) and far from creating a perfect world, economic competition often encourages behaviours that not only cause enormous harm to the group but also provide no lasting advantages for individuals, since any gains tend to be relative and mutually offsetting (Frank 2012). Other theories, such as the evolutionary theory and institutional economic theories, for example, as well as the 'varieties-ofcapitalism approach' (Hall and Soskice 2001) and national business system (Whitley 2000), though sometimes regarded as unorthodox, can better explain the organisation of markets. According to this view, various institutions are present in both contextual and transactional ecosystems and influence the organisation of markets. Players in such ecosystems try to fulfil their interests by seeking ways to position themselves in the institutional environment and by actively trying to use it to their advantage (Jaklič 2009). In an institutional environment, linkages among players and institutions are crucial for successful market organisation and a con- 
dition for market efficiency. Lack of linkages present a systemic failure and can have crippling effects on market efficiency. To enable the creation of linkages, and with it the efficiency that market can bring, a uniform regulatory environment needs to be established.

The need for a new framework for regulatory cooperation was - and continues to be - the most critical in the case of wholesale markets and socalled horizontal networks (Agency for the Cooperation of Energy Regulators 2018). Namely, to a great extent the formed wholesale electricity market exhibits the features of a natural monopoly that does not contribute to competitive pricing as in other sectors of the economy (Abrhám et al. 2015). According to Lisin et al. (2017), integration of certain energy systems and energy markets results in the gradual equalisation of basic prices and a shift in the financial and economic policy of energy sector companies towards optimisation of the energy system.

The integration of wholesale markets relies on cross-border cooperation and it cannot be expected that development is effectively supported and controlled by NRAS whose cooperation is purely voluntary. The same consideration applies to the development of European energy networks. Consequently, to ensure the effective integration of energy markets and energy networks at an EU level, a regulatory framework was required - one that would be more effective than what could be achieved through voluntary NRA cooperation.

This paper will examine the process, goals and results of the establishment of the common EU energy market, which is now known as the internal energy market. One of the key elements of this process was the establishment of the common regulatory framework. Its key element was the establishment of the Agency for the Cooperation of Energy Regulators.

\section{The Agency for the Cooperation of Energy Regulators and the Evolution of Its Role}

As part of the institutional framework set out by the Third Energy Package, known as the Clean Energy Package (CEP), Regulation (EC) No 713/2009 (European Parliament and Council 2009a) brought about the establishment of the Agency for the Cooperation of Energy Regulators. Its purpose (set out in paragraph 2 of Article 1) was to assist the national regulatory authorities (NRAS) in exercising, at an Eu level, the regulatory tasks performed in the member states and, where necessary, coordinate their action. The agency was therefore meant to fill the regulatory gap 
in cross-border issues, which was created during the establishment of the internal energy market because NRAs had mostly national powers and competences. ACER was to play a key role in the liberalisation of European electricity and gas markets.

The reasons for establishing ACER, as summarised from the preambles of the ACER Regulation (European Parliament and Council 2009d), are as follows:

In the Commission's Communication of 10 January 2007 entitled 'An Energy Policy for Europe' (European Commission 2007), the EC stressed the importance of completing the internal electricity and natural gas markets. One of the key measures identified as being necessary to achieve this objective was improving the regulatory framework at the Community level. The EC established an independent advisory group on electricity and gas, called the European Regulators Group for Electricity and Gas (E RGEG) (European Commission 2003) to facilitate consultation, coordination, and cooperation between the regulatory bodies in member states, and between those bodies and the Commission, to consolidate the internal markets in electricity and natural gas. The group was composed of representatives of the NRAS established in line with Directive 2003/54/EC (European Parliament and Council 2003a) of the European Parliament and of the Council of 26 June 2003 concerning common rules for the internal market in electricity and Directive 2003/55/EC of the European Parliament and of the Council of 26 June 2003 concerning common rules for the internal market in natural gas (European Parliament and Council 2003b). As ERGEG's work since its establishment has made a positive contribution to the internal markets in electricity and natural gas, especially in terms of providing independent solutions to aid in the establishment of the EU's internal market, ERGEG proposed that voluntary cooperation between NRAS should take place within a Community structure with clear competences and with the power to adopt individual regulatory decisions in several specific cases. In March 2007 the European Council invited the Commission to propose measures to set up an independent mechanism for the cooperation of national regulators (NRAs).

The key areas of cooperation as outlined in the said regulation are (European Parliament and Council 2003a):

- regulating the internal market

- eliminating obstacles to cross-border electricity and natural gas exchange 
- later (following the adoption of REMIT) monitoring and controlling the operation of the internal market (wholesale level)

The decision by the European Council and European Parliament to draw up a special regulation to outline ACE R's operations (European Parliament and Council 2009a) was approved in the framework of the Third Energy Package of directives on the regulation of the internal electricity and gas market, which was followed by the regulation on conditions for access to the network for cross-border exchanges in electricity (European Parliament and Council 2009b) and the regulation on conditions for access to the natural gas transmission networks (European Parliament and Council 2009c), along with others (establishing ENTSO-E and ENTSOG) (European Parliament and Council 2009a).

To ensure adequate harmonisation of the applicable rules, the ACER Regulation states that ACER has an important role in developing framework guidelines with which network codes must be in line. It also highlights its role in reviewing network codes (both when created and upon modification) to ensure that they are in line with the framework guidelines (European Parliament and Council 2009a).

According to the European Commission, an essential factor in establishing single markets is a unified approach to monitoring the development and conditions in the market. ACER was therefore tasked with monitoring regional cooperation between transmission system operators (тSO) in the electricity and gas sectors as well as executing the tasks of the European Network of Transmission System Operators for Electricity (ENTSO-E), and the European Network of Transmission System Operators for Gas (ENTSOG). ACER's involvement is essential to ensure that the cooperation between Tsos proceeds efficiently and transparently (Energy Agency 2019).

In line with the general $\mathrm{EU}$ guidelines for establishing an internal energy market and to ensure the security of energy supply, member states had to start cooperating closely and remove barriers to cross-border electricity and gas exchange. Based on an impact assessment of the resource requirements for a central entity, it was concluded that an independent central entity offers many long-term advantages over other options. A need, therefore, arose for the establishment of an agency for the cooperation of energy regulators, to fill the regulatory gap at the Community level and to contribute to the effective functioning of the internal electricity and natural gas markets (Energy Agency 2019). Agency for the 
Cooperation of Energy Regulators (2018) itself has described the need for regulatory unification to assure the emergence of a common retail electricity market: 'However, despite the ambition in the 1990s to set up a pan-European retail market, the markets supplying energy to end consumers are still mostly national in scope, as they must consider the different patterns of consumer behaviour, which are a result of historical and cultural differences. Although we need to do everything in our power to bring forth the liberalisation of national retail markets and ensure that competitive suppliers have non-discriminatory access, the implementation of provisions on retail markets and consumer protection are by nature national issues, so the agency was granted limited competences in these areas, mostly relating to monitoring.'

The increasing integration of wholesale energy markets and the resulting increase in cross-border trade volumes raised the question of how to ensure the integrity and transparency of these markets. Transparency is understood as timely, effective, and non-discriminatory access to the same important information relating to prices for all market participants. Transparency, therefore, gives all market participants confidence that they are trading based on the same information. Integrity, on the other hand, calls for the prevention of market abuse. In this sense, the integrity of energy markets gives consumers confidence that the prices at which they purchase electricity reflect a fair supply/demand ratio as well as, more generally, the market fundamentals, states the agency's document.

ACER is therefore expected to provide an answer to the issue presented of the incomplete establishment and functioning of the EU's internal energy market. In essence, a regulated energy market should bring greater:

- competitiveness, connected to the economic development within the $\mathrm{EU}$,

- security of supply, relating to the EU's social dimension,

- sustainability, which presents the answer to the climate and energy challenges.

In May 2011 the Commission also adopted a decision to repeal Decision 2003/796/EC on establishing the European Regulators Group for Electricity and Gas (European Commission 2003), through which ACER also took over the tasks that had until then been assigned to the European Regulators' Group for Electricity and Gas.

Although the agency was founded as a driving force of greater cooperation between NRAS, its role concerning the regulators continued to 
evolve and the ratio between the role of the agency and that of the NRAS gradually changed, for example in the case of implementing Regulation (E U) No 1227/2011 of the European Parliament and the Council on Wholesale Energy Market Integrity and Transparency (European Parliament and the Council 2011). This aspect of the agency's operations, along with other aspects that have complemented its initial mandate, are recognised in the recast ACER Regulation, which is part of the Clean Energy for All Europeans package of legislative proposals. The regulation (Agency for the Cooperation of Energy Regulators 2018) states that 'ACER shall also contribute to the establishment of high-quality common regulatory and supervisory practices, thus contributing to the consistent, efficient and effective application of Union law to achieve the Union's climate and energy goals.'

According to one of the very prolific authors in the field of energy, Erkan Erdogdu (2011), one of the main objectives of any economic reform is to bring changes in the institutional arrangement so that economic activities can be performed more efficiently. In addition, reforming any sector in an economy requires changing the institutional environment, changing the organisational structure and modifying the governance mechanism. Since the late 1980 os, power market reform has become the standard prescription of the multilateral donor agencies such as the International Monetary Fund ( $\mathrm{MF}$ ) and the World Bank, and reform programmes have been implemented vigorously for about three decades now. Although the content of each reform programme has differed from one country to the next, the policy of functional disintegration, the establishment of regulatory authorities, the formation of wholesale and retail power markets and the privatisation of the electricity industry have been generally regarded as the natural components of a reform programme without paying much attention to the institutional environment of the country (Erdogdu 2013). The author also claims that 'despite the different approaches in the design of regulatory institutions, a separate agency from the government with reasonable levels of autonomy and technical expertise has emerged as the preferred model for a regulatory institution, which could also be applied to ACER and its role in the development of the Eu energy market.

Erdogdu (2016) also reminds us that the most important step in European power market integration took place on 4 February 2014, when price coupling in North Western Europe (NWE) went live. 'Since the launch of NWE, two extensions have taken place. Spain and Portugal joined in May 
2014, while Italy coupled with France, Austria and Slovenia in February 2015. As a result, the coupled area was named the Multi-Regional Coupling (MRC), which now covers 19 countries and represents about 85\% of European power consumption,' writes Erdogdu (2016). In an article published in 2011 entitled 'What happened to efficiency in electricity industries after reforms?' he claims: 'The true value of electricity reform is a matter of empirical testing rather than theoretical debate.'

In practical situations, it is often the case that regulatory policy is pursued both locally and globally. For example, each state has its own regulatory policies and regulatory institutions, but there are common policies and institutions that seek to produce additional social benefits by coordinating regulatory policies and promoting the common interests of the Union, writes Sabolić (2016), adding that in this case, this 'supranational' regulator faces the same problems of limited rationality that local regulators face at their local level (for the purpose of this paper, the chair of the ACER's administrative board argued that naming ACER as a 'European Energy Regulator' would be wrong, since the agency's full name Agency for Coordination of Energy Regulators - clearly states what its role is). In this case the joint regulator formulates its regulatory policy tools partly based on input from local regulators and partly at its discretion. This time, as local regulators belong to sovereign states and there is no possibility of absolute control by the joint regulator, individual local regulatory policies will not be mapped unchanged to supranational policy, but local regulators will reject the extent to which they filter information by the joint regulator, and by doing so try to achieve or maintain their own local interests. In general, the variance of local regulatory policies, as viewed by an incompletely informed joint regulator, to which the national regulators are "lying" to some extent, may be greater than the variance of the same policies when viewed by local regulators. On the other hand, due to the uncertainty further compounded by the regulatory moves of the joint regulator, the variance of local policies may also become larger for local regulators. While they only serve the common regulator of local politics as a source of information (somewhat corrupted by deliberate filtering), local regulators are the primary tool of action. In any case, a situation involving a joint regulator, which does not have full authority over the local authorities, may lead to an increase in information asymmetry and therefore to a deterioration in the regulatory policy portfolio at the local level, or to a deterioration in the quality of information received by the regulator at a global level (Sabolić 2016). 
According to Sabolić (2016), the global regulator may seek to 'improve' its own portfolio through synergies and policies of common interest. To what extent it will succeed in this is difficult to assess in the general case. In this situation, the global regulator and local regulators enter into a strategic competition, at least in part, an uncooperative strategic game of information filtering. The outcomes of such games may be better, equal or worse than the ordinary sum of the effects of local regulatory policies, which depends on many factors, but, first and foremost, on the success of formulating a common regulatory policy in circumstances where it cannot be firmly imposed, whilst it also depends on the will of the individual participants in the game, not just the will of the central regulator. However, they can never be better than the outcome of a regulatory process in which a policy is formulated by only one regulator, common to all jurisdictions. Namely, the 'unitary regulator' is not confronted with the additionally introduced asymmetry of information, and it can fully extract the benefit of all local policies, and add to its overall policy mix its own policies, hoping for an increase in shared well-being (Sabolić 2016).

The first of the key roles assigned to the agency by the Third Energy Package, which has kept it busy during its initial years of operation, was to contribute to the development of framework guidelines and network codes, which, in line with their purpose, set out a consistent set of rules for the internal energy market. It is, therefore, necessary to assess whether these rules were adequately implemented and whether they had the intended effects and benefits - mainly relating to energy consumers - with the latter being the ultimate aim of the entire market integration project. This will be the main hypothesis of this research.

For this purpose, exactly ten years after the establishment of ACER, the authors of this paper set out to check its effectiveness in establishing and ensuring the operation of the internal energy market in the $\mathrm{EU}$. The paper was drafted as a case study of the E U's internal energy market, exploring the role of the principal player - ACER - the only European agency of its kind in the field of energy. It must be stressed that the focus of this study is to paint a general perception of national regulators, whose cooperation the agency is in charge of, and energy traders (companies that retail electricity to final consumers) as market players.

\section{Methodology}

Although the authors are aware that ACER's success could be measured differently - through more econometric and therefore quantitative re- 
search methods - the qualitative research method was used in order to get the information directly from the market participants, since they are active market players. The purpose of this research is to determine the level of satisfaction among NRAS and energy traders with the work done by ACER, whose main task is to establish the internal energy market and to make sure that it functions. The authors wanted to not only check the perception of NRAS and traders of ACER's functionality but also to examine their expectations regarding the future of this unique institution in the energy market, that is, the future of ACER and what kind of importance the regulators attach to this institution today.

The authors began by carrying out in-depth interviews with the first director of ACER and the director of the Slovenian NRA, and then moved on to examining the issues by using a questionnaire to conduct a survey among NRAS and energy traders in the EU.

The interview with the first director of ACER, Alberto Pototschnig, took place in April 2019. The conversation was recorded on a mobile phone, it took 43 minutes and was conducted in English.

The interview with the director of the Slovenian NRA, Duška Godina, took place in May 2019. The conversation was recorded on a mobile phone, it took 40 minutes and was conducted in Slovenian.

After carrying out the first part of research with the implementation of interviews, a survey questionnaire was prepared (see the Appendix), which was sent via email to all the NRAS in the $28 \mathrm{EU}$ member states (Brexit had not yet taken place at the time of the survey) and 30 energy traders operating in the $\mathrm{EU}$ (individual traders are present in more than one state).

The authors were able to secure a representative sample for quantitative research: nine representatives of NRAS operating in European energy markets - a third of all possible respondents among regulators (some NRAS responded that they did not wish to take part in the survey) and ten representatives of energy traders - a third of all the possible respondents among traders (some traders responded that they did not have time to take part in the survey).

\section{Results and Recommendations}

This research has shown that the NRAS and energy traders who participated in the survey mostly agree on the fact that the $\mathrm{E} U$ has a nearly functional internal energy market.

Their answers are shown in table 1. Based on these results, it can be 
TABLE 1 Responses to the questions

\begin{tabular}{|c|c|c|c|c|}
\hline \multirow[t]{2}{*}{ Response } & \multicolumn{2}{|c|}{$\begin{array}{l}\text { Does the EU Have a } \\
\text { Well-Functioning Internal } \\
\text { Energy Market? }\end{array}$} & \multicolumn{2}{|c|}{$\begin{array}{l}\text { Has the Agency for the } \\
\text { Cooperation of Energy } \\
\text { Regulators Been Key to the } \\
\text { Functioning of the Internal } \\
\text { Energy Market? }\end{array}$} \\
\hline & NRAS & Energy traders & NRAS & Energy traders \\
\hline Disagree & $\mathrm{O}$ & $\mathrm{o}$ & $\mathrm{O}$ & $\mathrm{O}$ \\
\hline Somewhat disagree & 1 & 2 & 1 & 2 \\
\hline Neutral/don't know & 0 & 0 & o & $\mathrm{o}$ \\
\hline Somewhat agree & 8 & 6 & 8 & 6 \\
\hline Agree & 0 & 2 & o & 2 \\
\hline
\end{tabular}

concluded that NRAS and energy traders mostly agree on the fact that the $\mathrm{EU}$ has a nearly functional internal energy market.

Nevertheless, the comments of two NRAS who replied to the question about what still needs to be done for a well-functioning internal energy market should not be overlooked. One of the comments was that instead of striving towards the lowest possible energy prices for consumers, work should be done on lowering $\mathrm{CO}_{2}$ emissions. This should, therefore, act as a governing strategy for the internal energy market. The second comment, on the other hand, mentioned Nominated Electricity Market Operators (NEMOS), suggesting that a single operator should be established for the entire internal energy market for successive periods of 5 to 10 years.

Not all respondents answered the authors' question about whether ACER has been effective in establishing an internal energy market, however those that did, believe that the agency has been effective in this regard. The question about whether ACER has been effective in ensuring the functioning of the internal energy market was also not answered by all the respondents, however those that did, believe that it has. Most of the respondents - both NRAS and energy traders - agree that ACER has been key to the functioning of the internal energy market. The answers are shown in table 1.

However, it should be stressed that the research is based on the perception of the selected target group (e.g., NR AS and energy traders) and that the results do not necessarily represent the 'absolute truth.' Moreover, the authors suggest that further research needs to be conducted - such that a quantitative research method would also be used. 
Meanwhile, the responses to the question about whether ACER's effectiveness depends mostly on its director were quite mixed, with a large number of the respondents replying that it does not. Nevertheless, the answers to the follow-up question should not be dismissed: If it does not depend on the director, what does it depend on? One of the responding NRAS stated that 'the effectiveness of ACER is dependent upon good cooperation between the director and the Board of Regulators (BoR).' Another NRA replied: 'the effectiveness of ACER depends mostly, perhaps solely, on the disciplining of Tsos and regulators through the interplay between the decision-making procedures [...] set in the European network codes and the European network guidelines.' A separate NRA said that 'a sufficient number of employees and financial resources are indispensable for the effectiveness of ACER,' while another emphasised the importance of 'well-trained and competent staff.' Well-trained staff, professionalism, the right competencies, and the ability to work in a team were also mentioned in the energy traders' answers to the follow-up question. Their responses also reveal that energy traders are aware of the fact that a broader support environment - encompassing everything from the legislative framework to the NRAS - is required to ensure ACER's efficiency.

It can, therefore, be concluded that, when asked about whether ACER's efficiency depends on its independence, although the respondents (both NRAS and energy traders) chose nearly all of the possible answers (except the first one, 'disagree'), most of them agreed that the efficiency of the agency does ultimately depend on its independence. There were also two noteworthy answers to the follow-up question: If ACER's efficiency does not depend on its independence, what does it depend on? One of the NRAS reiterated its answer to the previous question: 'The effectiveness of ACER depends mostly, perhaps solely, on the disciplining of TSOs and regulators through the interplay between the decision-making procedures [...] set in the European network codes and the European network guidelines', while another said that 'independence is a precondition, but not a guarantee for success. Successful operation necessitates the right competencies and a sufficient budget.'

It can, therefore, be concluded that, when asked about whether ACER's independence depends on its management, although the respondents (both NRAs and energy traders) chose all of the possible answers, most of them agreed that it does.

It can also be concluded that the respondents (both NRAS and energy traders) have differing opinions on whether ACER's independence de- 
pends on its budget, as they chose nearly all of the possible answers to this question (except the first one, 'disagree').

There were also quite interesting responses to the question about whether the taking away of some of the director's powers and increasing those of the Board of Regulators, as set out in the recast ACER Regulation, was a positive development. While most of the NRAS support the modification, not all of the energy traders see it as a truly positive development. One of the traders explained that the development was not positive due to the 'collective perpetuation of the status quo.' Another energy trader stated that 'this approach will further increase the influence of local regulators and local interests,' whereas one said that 'considering the Board's composition, the risk of "bland compromises" is even greater. The NRAs that saw this as a positive development mostly supported their decisions by saying that this will also increase the influence and power of NRAS - something energy traders are certainly not too pleased about. However, the energy traders that did see this as a positive development explained that the NRAS which will thus gain more power are also more acquainted with the local content and the specifics of certain environments. They added that this will ensure that ACER's position on relevant topics is the most neutral and professional. One of the energy traders also emphasised that although it is a good idea to take away power from a particular person and give it to several people, it is necessary to ensure that not too many people take part in the decision-making process.

ACER should take into consideration, on a professional basis, all the comments and opinions submitted both by the NRAS and the energy traders, since these players form an integral part of the internal energy market and ensuring the best possible operation of the internal energy market will depend on the cooperation of all the players.

\section{Conclusion}

It can be concluded that the expectations of the respondents (both NRAS and energy traders) regarding the effectiveness of ACER in establishing the EU's internal energy market have so far mostly been met. However, the neutral responses of some of the traders and the negative responses from a small number of respondents should not be overlooked, especially one very clear comment made by one of the NRAS: 'The formal procedures and the substantial reasoning in respect of ACER's Decision No. 04/2019 of 1 April 2019 on the determination of CCRS etc. had the character of a 'coup d'état.' Notably, the proceedings leading to the wording 
of Article 6 on Future Amendments within Annex I on the decision in question failed to meet the requirements for 'good administration', transparency, the right to be heard etc. set in Article 41(1) to (2), ref. to Article 51(1), in the Charter of Fundamental Rights of the European Union.'

Additionally, it can be concluded that when it comes to the expectations regarding the effectiveness of ACER in ensuring the functioning of the EU's internal energy market, only a few respondents, including NRAS and energy traders, said that their expectations have been met. However, it is worth noting that several respondents chose the neutral response, while one of the traders wrote in the email reply: 'For us traders, ACER means greater transparency, and consequently fewer opportunities. On the other hand, investments in non-transparent markets are better valued.' NRAS were in the majority among the respondents whose expectations were mostly met.

When replying to the question about their specific expectations regarding ACER's future activity, one of the NRAS mentioned 'the continued solidification of ACER's reputation as a professional European institution which promotes cooperation between EU NRAS, making professional and transparent choices that support both the implementation of the Clean Energy Package (CEP) and the functioning and control of the E U's internal energy market.' Another NRA said that 'the importance of ACER will grow further as the internal energy market develops.' A different NRA stated: 'We are very concerned about the reduction of financial resources allocated to ACER and we are afraid that in the future ACER will not be able to fulfil all the tasks assigned to it, especially those related to REMIT.' A separate NRA said that 'ACER could have more say in solving the problems of third countries,' while another regulator stated that it expects 'increased emphasis on ACE R's role as an advisor for NRAS on issues related to the implementation of regulatory requirements and transposition of the directives and improved energy market data quality and exchange.' A separate NR A noted that 'the Clean Energy Package, notably the recast ACER Regulation, seems likely to improve the effectiveness of ACER's future activity, as the regulators of member states, in respect of their collective decision-making via the Board, are likely to be more involved in the preparation for the Board's decision-making, and in the following implementation within each of the member states of the decisions having previously been adopted by the Board.' The final NRA said that 'we expect ACER's workload to increase especially in terms of the decision on cross-border cases (as per art. 6(10) New ACER regula- 
tion) as the internal market becomes increasingly interconnected and integrated. We expect ACER to improve its decision-making in terms of a fair process, evidence and regard to the complexities of interconnected grids. The new ACER rules of procedure and resource availability will be key to this.'

Turning now to the expectations of energy traders. One of them noted that it expects 'faster implementation and operation of adopted regulations,' whereas another pointed out 'the establishment of a market where the countries are interconnected at all levels and which features clear, easily accessible and presented connections for approved flows between bidding zones.' Another trader mentioned 'supporting the further integration of the $\mathrm{EU}$ internal energy market based on the now approved EU Clean Energy Package legislation and enabling market-based regulation for applying new technologies in demand flexibility, energy storage, sector coupling, hydrogen energy, etc.', whereas a separate trader emphasised 'establishing a competitive environment in all segments of the energy market, focusing on advanced solutions and enabling their application in consumer services.' One of the traders also noted 'a focus on further harmonisation of the EU's internal energy market and closer monitoring of national markets' activities, regarding the implementation and execution of EU regulations (which should be "independent" from local/national politics).' A separate trader expects to see 'greater trust in the trans-European market, especially in the markets where the risks are higher, as well as boosting investment of western companies in eastern and Balkan markets', whereas the final energy trader said that 'ACER should continue to monitor the internal market, but it should be more open towards the market participants. [...] Their guidelines [ACER's guidelines on REMIT; authors' note] is rough and too general. There is simply no way of getting in direct contact with them. It makes the market participants' situation more difficult, when all they would like to do is to fully comply with ACER regulation.'

Even though the authors initially tried to answer the question of how successful ACER has been in promoting the internal energy market, which led them to investigate how successful traders and regulators believe ACER has been and how successful traders and regulators claim ACER has been in response to a survey, the authors are well aware that a survey alone will not provide answers to the first question. However, the research did produce an interesting view of how the most active market participants feel and perceive the main institution's contribution to mar- 
ket development. The authors also acknowledge that interviewees might not say what they believe in response to a certain question. For example, traders might have no particular interest in how well the internal market operates; their interest is in how profitable the market is to them and if it is highly profitable to them but the market is functioning poorly, they are unlikely to criticise arrangements that are highly advantageous to them. Regulators could also have their own reasons for giving answers that are strategically favourable to them. Nevertheless, the authors strongly believe that the conducted research brings a particular social desirability of the answers for the sector. In order to overcome the possible obstacles, such as insincere answers, the research assured the anonymity of the survey participants.

'Science explores, technology executes, man, conforms,' said Rifkin (2007), commenting on the necessary adjustments. Fittingly, the ultimate conclusion of this study, which examined the establishment and functioning of the EU's internal electricity market through the prism of the effectiveness of ACER - strictly through the eyes of NRAS and traders -, is that the agency, along with the entire ecosystem that supports its operation, must be ready to make certain adjustments, necessitated by future energy trends. Nevertheless, we can confirm the hypothesis of this paper: ACER was able to set out a consistent set of rules for the internal energy market and these rules were adequately implemented. Whether they had the intended effects and benefits - mainly relating to providing benefits to energy consumers and to bringing market mechanisms to the decisionmaking process in the industry - further, quantitative, research would be required.

As Felder (2016) notes, it is necessary to understand that more time is still needed for the development and reform of electricity markets and that it is still ongoing. At the same time, it is necessary to consider that no matter how a system or market is structured, organisations or other players will always act in their interest, as is the case in any other market.

\section{References}

Abrhám, J., Y. Bilan, A. Krauchenia, and W. Strielkowski. 2015. 'Planning Horizon in Labour Supply of Belarusian Small Entrepreneurs.' Economic Research 28 (1): 773-87.

Agency for the Cooperation of Energy Regulators. 2018. 'Agency for the Cooperation of Energy Regulators Programming Document 20192021.' Agency for the Cooperation of Energy Regulators, Ljubljana. 
Arrow, K., and G. Debreu. 1954. 'Existence of an Equilibrium for a Competitive Economy'. Econometrica: Journal of Econometric Society 22 (3): 265-90.

Ebrahimian, H., S. Barmayoon, M., Mohammadi, and N. Ghadimi. 2018. 'The Price Prediction for the Energy Market Based on a New Method Homayoun.' Economic Research 31 (1): 313-37.

Energy Agency. 2019. 'Agency for the Cooperation of Energy Regulators.' Energy Agency, Maribor.

Erdogdu, E. 2011. 'What Happened to Efficiency in Electricity Industries After Reforms?' Energy Policy 39 (10): 6551-6o.

Erdogdu, E. 2013. 'A Cross-Country Analysis of Electricity Market Reforms: Potential Contribution of New Institutional Economics.' Energy Economics 39 (c): 239-51.

Erdogdu, E. 2016. 'Asymmetric Volatility in European Day-Ahead Power Markets: A Comparative Microeconomic Analysis.' Energy Economics 56 (c): 398-409.

European Commission. 2003. 'Commission Decision of 11 November 2003 on Establishing the European Regulators Group for Electricity and Gas.' Official Journal of the European Union L 296/34-5.

European Commission. 2007. 'An Energy Policy for Europe.' сом(2007) 1 final, European Commission, Brussels.

European Parliament and Council. 2003a. 'Directive 2003/54/EC of the European Parliament and of the Council of 26 June 2003 Concerning Common Rules for the Internal Market in Electricity and Repealing Directive 96/92/EC - Statements Made with Regard to Decommissioning and Waste Management Activities.' Official Journal of the European Union L 176/37-55.

European Parliament and Council. 2003b. 'Directive 2003/55/EC of the European Parliament and of the Council of 26 June 2003 Concerning Common Rules for the Internal Market in Natural Gas and Repealing Directive 98/30/Ec.' Official Journal of the European Union L 176/5778.

European Parliament and Council. 2009a. 'Regulation (EC) No 713/2009 of the European Parliament and of the Council of 13 July 2009 Establishing an Agency for the Cooperation of Energy Regulators.' Official Journal of the European Union L 211/1-14.

European Parliament and Council. 2009b. 'Regulation (EC) No 714/2009 of the European Parliament and of the Council of 13 July 2009 on Conditions for Access to the Network for Cross-Border Exchanges in Electricity and Repealing Regulation (EC) No 1228/2003.' Official Journal of the European Union L 211/15-35.

European Parliament and Council. 2009c. 'Regulation (EC) No 715/2009 
of the European Parliament and of the Council of 13 July 2009 on Conditions for Access to the Natural Gas Transmission Networks and Repealing Regulation (EC) No 1775/2005.' Official Journal of the European Union L 211/36-54.

European Parliament and Council. 2009d. 'Regulation (EU) 2019/942 of the European Parliament and of the Council of 5 June 2019 Establishing A European Union Agency For The Cooperation Of Energy Regulators.' Official Journal of the European Union L 158/22-53.

European Parliament and Council. 2011. 'Regulation (EU) No 1227/2011 of the European Parliament and of the Council of 25 October 2011 on wholesale energy market integrity and transparency.' Official Journal of the European Union L 326/1-16.

Felder, F. A. 2016. Electricity Markets and Power System Economics: Book Reviews. Cleveland, OH: IAEE.

Frank, R. H. 2012. The Darwin Economy: Liberty, Competition, and the Common Good. Princeton, NJ: Princeton University Press.

Hall, P. A., and D. Soskice. 2001. 'An Introduction to Varieties of Capitalism.' In Varieties of Capitalism: The Institutional Foundations of Comparative Advantage, edited by P. A. Hall and D. Soskice, 1-70. Oxford: Oxford University Press.

Jaklič, M. 2009. Poslovno okolje in gospodarski razvoj. Ljubljana: Ekonomska Fakulteta Univerze v Ljubljani.

Léautier, T. O. 2016. The Visible Hand: Ensuring Optimal Investment in Electric Power Generation. Cleveland, OH: IAEE.

Lisin, E., Y. Marishkina, W. Strielkowski, and D. Streimikiene. 2017. 'Analysis of Competitiveness: Energy Sector and the Electricity Market in Russia.' Economic Research 30 (1): 1820-8.

Quirk, J. M. 2008. 'Globalization at Risk: The Changing Preferences of States and Societies.' Managing Global Transitions 6 (4): 341-71.

Rifkin, J. 2007. The End of Work. New York: Penguin.

Rončević, B., J. Šušteršič, P., Wostner, and T. Besednjak Valič. 2010. 'Quo Vadis, Slovenia? Between Framework Conditionsand Internal Capabilities.' Managing Global Transitions 6 (4): 341-71.

Sabolić, D. 2016. 'Ekonomska regulacija međuoperatorskog poravnanja i upravljanja zagušenjima na tržištu električne energije.' PhD dissertation, University of Split.

Smith, A. 1845. An Inquiry into the Nature and Causes of the Wealth of Nations. Edinburgh: Nelson.

Whitley, R. 2000. 'The Institutional Structuring of Innovation Strategies: Business Systems, Firm Types and Patterns of Technical Change in Different Market Economies.' Organization Studies 21 (5): 855-87. 


\section{Survey Questionnaire}

Scale: (1) disagree, (2) somewhat disagree, (3) neutral/don't know, (4) somewhat agree, (5) agree.

Part 1

Does the EU have a well-functioning internal energy market?

(1) (2) (3) (4) (5)

If you have answered 'disagree' (1) or 'somewhat disagree' (2) to question 1: In your opinion, is the process of establishing the internal energy market still underway?

(1) (2) (3) (4) (5)

If you have answered 'disagree' (1) or 'somewhat disagree' (2) to the previous question: What would you say still needs to be done for a wellfunctioning internal energy market?

If you have answered 'agree' to question 1: Has the Agency for the Cooperation of Energy Regulators (ACER) been effective in establishing the EU's internal energy market?

(1) (2) (3) (4) (5)

If you have answered 'agree' to question 1: Has ACER been effective in ensuring the functioning of the EU's internal energy market?

(1) (2) (3) (4) (5)

Has the Agency for the Cooperation of Energy Regulators been key to the functioning of the internal energy market?

(1) (2) (3) (4) (5)

Part 2

In your opinion, does the effectiveness of the Agency for the Cooperation of Energy Regulators depend mostly on its director?

(1) (2) (3) (4) (5)

If you have answered 'disagree' (1) or 'somewhat disagree' (2) to the previous question: What would you say the effectiveness of ACER depends on if not the Agency's director?

In your opinion, does the effectiveness of the Agency for the Cooperation of Energy Regulators depend mostly on its independence?

(1) (2) (3) (4) (5)

If you have answered 'disagree' (1) or 'somewhat disagree' (2) to the previous question: What would you say the effectiveness of ACER depends on if not the Agency's independence?

Would you say that the independence of the Agency depends on the Agency's management? 
(1) (2) (3) (4) (5)

Would you say that the independence of the Agency depends on the Agency's budget?

(1) (2) (3) (4) (5)

The recast ACER regulation that is part of the Clean Energy Package adapts the role of the Agency's director by taking away some of the director's powers in making decisions on substantive issues. The division of responsibility in decision making between the Board of Regulators and the director has been redefined in favour of the board. Would you say this is a positive development?

(1) (2) (3) (4) (5)

If you have answered 'disagree' (1) or 'somewhat disagree' (2) to the previous question: Why not?

If you have answered 'agree' (5): Why is this a positive development?

\section{Part 3}

Have the expectations of your organisation regarding the effectiveness of ACER in establishing the EU's internal energy market so far been met?

(1) (2) (3) (4) (5)

If you have answered 'disagree' (1) or 'somewhat disagree' (2) to the previous question: Why not?

Have the expectations of your organisation regarding the effectiveness of ACER in ensuring the functioning of the EU's internal energy market so far been met?

(1) (2) (3) (4) (5)

If you have answered 'disagree' (1) or 'somewhat disagree' (2) to the previous question: Why not?

What are your expectations regarding ACER's future activity? Please specify.

Thank you for participating in the survey. 